\title{
China's Urban Migrants: The Role of Ethnic Enterprises and Entrepreneurs
}

\author{
Zhang Jijiao \\ Institute of Ethnology and Anthropology \\ Chinese Academy of Social Sciences
}

Over the past few decades, most researches have focused on comparative study of the economic performance of different migrant groups in cities, or their economic participation patterns. In this paper, based on first-hand information of recent surveys in some cities of China, we use the "ethnic enclave" and its economic circle theory trying to illustrate that among various factors that have affected the formation of the ethnic economic-cultural pattern, the most important and substantial roles are played by the ethnic enterprises and the ethnic entrepreneurs.

\section{INTRODUCTION}

Since the Reform and Opening- up of China, the distribution pattern of ethnic groups in Chinese cities presented a "scattered" and "hybrid" trend, with large-scale population floating across regions and ethnicities and its city-oriented direction as its basic motivation. Some scholars worry that the fast process of urbanization will generate the "fragmentation" groups (Hao, 2017). Will all the border ethnic minorities migrating to a city with higher population heterogeneity be "fragmented"? And what changes will it bring to different ethnics?

Over the past few decades, most researches focused on the comparison of economic performance of different ethnic immigrant groups, or their economic participation. Chan Kwok Bun \& Claire Chiang (1994) wrote in their work Stepping Out:The Making of Chinese Entreprenuers: immigration is not a new topic, but linking immigration with entrepreneurship, to understand the process how the immigrants transformed themselves into small businessmen, businessmen, entrepreneurs and industrialists is quite novel. They got rid of the existing socio-economic structures and blocks, seized new opportunities for development, and created a new socio-economic structure. With this issue, we carried out the research work on the floating urban minorities (immigrants).

\section{LITERATURE REVIEW: STUDIES ON URBAN MIGRANTS, ETHNIC ENTERPRISES AND ENTREPRENEURS}

During 1970-1980, there were conducted a number of studies on the Chinese community (especially Chinatown). V. Nee and B. Nee (1973) conducted investigation and researches on the Chinese community in America. They are mainly focused on a variety of factors that affect the economy and the economic success of Chinese immigrants gathered in the region. B.P. Wong's study found that the relation between entrepreneurs and migrant workers in Chinatown lies in that the entrepreneurs provide shelters and 
protection to the new immigrants and act as brokers for the immigrants. While providing assistance to the Chinese immigrants, the entrepreneurs also derive large profits from the business (Wong, 1988). Peter Kwong organized empirical research on New York Chinatown's evolving process from the 1930s to the $1950 \mathrm{~s}$, in which in-depth analysis of the labor market and laborers' living condition were revealed. He believes that in the immigrants gathering zone like the New York Chinatown, the foremen utilize the immigrants who are not familiar with the new environment to make huge profits through low wages, poor working conditions and extended working hours, and other means. Thus those foremen became the nouveau riche, while a large number of migrant workers still live in poverty. In short, in Chinatown, these bigwigs took the cheap immigrants labor as their new wealth accumulation tool and a ladder to climb to a higher class in the United States ( Kwong, 1979). In a later follow-up study, Peter Kwong still insisted that, whether it is in the old Chinatown, or in the new Chinatown, they all are places of exploitation of the Chinese immigrants, and most Chinese as members of the ethnic enclave have been living in poverty (Kwong, 1987).

Alejandro Portes and Robert Bach proposed the "ethnic enclave" and its economic circle theory in 1985 or the "ethnic socio-economic enclave" theory (Portes and Bach, 1985). Alejandro Portes and L. Jenson in 1989 conducted an empirical study toward the theory. In the research on the Cuban immigrants enclave in Miami, they found that, on one hand, the Cuban enterprises of the enclave are more adept at taking advantage of the American economy to gain greater profits and gains than the enterprises outside of the enclave; the Cuban immigrants inside the enclave can better utilize their human labor resources to obtain higher pay and status in the low-end labor market than the Cuban migrants outside of enclave. On the other hand, the common cultural foundation, the sense of ethnic identity and the ethnic solidarity of the Cuban enclave both help the ethnic entrepreneurs, and the migrant workers to get rid of the variety of adverse factors in the American community (such as racial discrimination etc.) and to better integrate into the society, and to get a higher income and social status (Portes and Jenson, 1989). On the whole, the formation and development of the ethnic socio-economic enclave mainly depend on three factors: economy, culture, and social networks. First, the structure of ethnic enclave's economy is consistent with the mainstream economy. However the development of the enclave's economy largely depends on its unique mode of operation and its labor market, thus its function is different from the "big economy". The ethnic enclave's economy supports its own ethnic industry and commerce, and helps immigrants improve their surviving ability and social status. Second, the immigrants in the enclave form its unique social network, consequently leading to expansion of group scale and the enclave range. Meantime the social network also provides a wealth of labor, goods and services markets for the development of the enclave. Third, the sense of ethnic identity and the ethnic solidarity within immigrant groups effectively promote the development of ethnic industry and commerce creating more employment opportunities. The development of the enclave's economy and the frequency of social interaction also stimulate the ethnic traditional culture to blossom. For example, the characteristic ethnic and cultural recreational industries quickly grow up and are strengthened. The interaction and mutual promotion of these three aspects has brought the enclave with vitality, and also improved the enclave's status in the big society.

Female scholar Zhou Min is one of the major American scholars who studied the Chinese immigrants and their enclave area. Inspired by Portes's economic enclave theory, she held a positive and optimistic attitude to New York's Chinatown. In the 1990s, she studied the history of Chinatown's development process which involved the Chinese immigration history, compared the differences between the early settlers and the new immigrants, and examined the structure and development of the economy of Chinatown, analyzed the characteristics of Chinatown's labor market and women's role and status in Chinatown, and finally made optimistic forecasts about future development of Chinatown. From a new angle, her research depicted the history, the present and the future of the development of New York's Chinatown. Although Chinatown once indeed acted as refugee camp, but later it has evolved into a major ethnic economy having great flexibility and strong vitality. She also noted that the Chinatown is not like most immigrants' ghettos or slums, but it is truly an area for developing careers. The Chinese immigrants 
and their descendants have established a large number of independent local small businesses in the town, which helped the Chinese immigrants to become one of the most developed and affluent immigrant groups in the immigration history of the United States. This is not the result of scheming or carefully planning by the Chinese immigrant entrepreneurs, but rather an adaptive response to the harsh realities of American society (Zhou, 1992).

In recent years, the city's ethnic diversity has become more evident, and many scholars began to focus on the intergroup relations in the ethnic business environment (Light and Gold, 2000). One path of research is to investigate the intergroup relations between buyers and sellers. The main concern of this kind of research is the intergroup interaction patterns of the Korean business owners, especially the conflicts in the black areas. Some scholars have compared the conflicts between the Koreans and the blacks in New York and in Los Angeles, and discovered that the local political groups (e.g. community associations) were the main cause strengthening factors of conflicts (Joyce, 2003). Some scholars have pointed out, the conflict between the black economy and the Korean economy reflects the Korean businessmen's unique status as the middleman in the economic structure (Weitzer, 1997). These studies show that Mexicans and Koreans regarded each other as commercial rivals, because both the two groups have a lot of immigrants. Another line of researches analyze the differences of various ethnic groups and their problems. A scholar, who made field observations and interviewed some South Korean business owners in Chicago and Los Angeles, noted that the prejudice South Korean business owners held against blacks is greater than that of the Latinos. Because before immigration Koreans already held erroneous prejudices against blacks, and after immigration, due to lack of communication, this bias has been further strengthened (Yoon, 1997). Another scholar pointed out that the status difference and different cultural expectations of immigrant business owners and local residents, and sometimes the language barriers, can lead to conflicts between groups (Lee, 2002).

Through the comparative study of ethnic enterprises of Chinese, Japanese and the blacks in the United States, Ivan Light (1972) found that the ethnic enterprises and their economic development are different from the mainstream capital economy. General capital companies rely on the class resources, i.e., the labor capital and financial capital; while the ethnic enterprises rely on ethnic resources, such as the close social relations and various ethnic cultural resources in the community. The workforce, funding sources and markets of ethnic enterprises are connected with ethnic resources, but also affected by the ethnic culture values, customs and way of life, etc.

\section{THEORETICAL FRAMEWORK}

In many regions of China, local resource allocation and economic-social development have presented a strong characteristic of "umbrella society", that is, a major driving force of China's economic development is still like the "umbrella relation" between local governments and enterprises (Zhang, 2016). What is common people's role in Chinese huge market transformation? Are they beneficiary or impaired party? To discuss such a complicated economical social structure transformation (especially market transformation) of China, the sole concept of "umbrella society" is apparently insufficient. As a broader concept of "umbrella society", common people's economic social life is a type of "beehive society". In the process of transition from planned economy to market economy, it allows common people to achieve higher beneficial opportunity and surplus allocation opportunity, which improved the labor enthusiasm; therefore, self-employed, vendor, private owner, blue-collar, white-collar worker, professional manager and freelancer are increasing. We depict this common people's high involvement of market development as "beehive society", in other words, every person is building up her own relationship network-beehives through personal or family's efforts (Zhang, 2018).

Portes et al (1985) believe that the mass existence of ethnic enterprises in the North American cities provides job opportunities to the ethnic minority groups and also accumulate wealth to improve the ethnic economic development and support. My own above concept "beehive society" is very similar with 
Portes's "ethnic enclave" or the "ethnic socio-economic enclave", which would possess certain reference value for further exploring the function of ethnic enterprises and entrepreneurs in the formation of a new economic-cultural pattern.

\section{The Sources of the Data}

The main sources of statistical data in this article came from a priority project of Chinese Academy of Social Sciences: Floating Urban Minorities and Its Scattering Dwelling Trend. The project was officially established in the second half of 2006, and fieldwork and data processing work were completed in the first half of 2008. We chose four representative cities: Hohhot of north China, Qingdao of east China, Shenzhen of southwest and Kunming of south China. Questionnaires and in-depth interviews were the two main methods we used during the study.

\section{The Analysis of the Data}

\section{Four Cities: The Basic Conditions of Six Ethnic Groups}

We visited the four cities (Qingdao, Kunming, Huhhot and Shenzhen) and found livelihood strategy and the economic power as the main ground factors. Our survey shows that among the six ethnic minorities, the primary means of access to the current work of the Korean, Mongolian, Hui and Bai is to "apply by themselves" (48.1\% -60.0\%), while the other two ethnics Yi and Dai is "through friends and colleagues' recommendation" (26.7\% -36.1\%). Among the six ethnic groups, Dai, Hui, Bai, Yi and Mongolian respondents have the high proportion of monthly income below 1,000 yuan, and the Dai respondents have the highest proportion $(50.0 \%)$. Korean respondents' income level is relatively higher with monthly income of 3,001 yuan and above, which accounts for 36.7\% (Zhang 2009, Zhang 2012.

The concentration of industries and the habitant aggregation are also very important factors, on which the ethnic socio-economic enclave theory is proposed accordingly. For example, in Kunming, there are about 10 thousand Huis who migrated from Xinjie Town, Huize County. They set up 9 cattle farms, holding $90 \%$ of Kunming's red meat market, of which the two biggest Huis enterprises are Mu Shengda and Mu Hongda. On December 28, 2007, we visited Mr. Mu Hongda, who owned 60-70 \% market of cattle slaughtering business in Kunming. We can see in terms of economic activity, the Hui migrants occupied most of the trade and slaughtering business of live cattle market and beef, mutton market in Kunming. In Kunming, the Dai and the Bai ethnic groups are also trying to develop food service, ethnic handicrafts and cloth trade and so on.

Our survey shows that in terms of industries they are currently engaged in, among the six ethnic groups surveyed in the four cities (Qingdao, Kunming, Huhhot and Shenzhen), Mongolian respondents possess the highest industry concentration $(83.9 \%)$ in catering services; Hui, Bai and Dai respondents also have high degree industry concentration (64-69\%) also in "catering services"; Korean respondents hold the lowest industry concentration (23.5\%) in manufacturing sector. Hui and Mongolian respondents are engaged in only one industry that concentrates more than $10 \%$ of their population, which is "catering services"; Bai and Yi respondents are engaged in two industries, namely the "catering services" and the "entertainment services"; Dai respondents also have two industries," catering services" and "domestic service"; Korean respondents have three sectors, namely "manufacturing sector", "commercial trade" and "catering service".

Our survey shows that the profession of the urban ethnic migrants mainly can be classified in three categories: (1) ordinary workers, most of them working in the construction sites, home-moving companies and labor-intensive industries, mainly from Southwest and Central south, accounting for more than $83 \%$ of the flowing population; (2) minorities from Qinghai, Gansu, Xinjiang, Ningxia, such as Hui and Uygur, engaged in trade and commerce, mainly dealing with beef, mutton, noodles and raisins, accounting for more than $14 \%$ of the flowing population; (3) itinerant traders mainly from Sichuan, Qinghai, Guizhou, Xinjiang and Tibet, such as the Hui, Uygur, Tibetan, Miao and other ethnic groups, 
mostly selling knives, jewelry, leather goods, accounting for $3 \%$ of the floating population. (Zhang and Yin, 2013).

Our survey also shows that among the six ethnic groups, the proportion of the Yi $(63.9 \%)$ and Hui $(64.3 \%)$ respondents working in private sectors is higher than the Bai, Mongolian and Dai respondents, far higher than the Korean respondents; the proportion of Korean respondents (35.4\%) working in the "joint ventures" is much higher than the other five ethnic groups; the proportion of self-employed Mongolian respondents (46.0\%) is higher than the other five ethnics. The first row of positions that the six ethnic groups' respondents hold is "corporate general staff", but with different proportions, in descending order the Yi (69.0\%), Hui (58.5\%), Mongolian (57.7\%), Bai (52.2\%), Dai (48.3\%), Korean (23.1\%). The position that held more than $10 \%$ of the four groups of respondents (Yi, Hui, Bai and Dai) is concentrated in the "corporate general staff" (48.3\% -69.0\%). Except for the position of "corporate general staff", there is a certain percentage of Mongolian respondents that assume the "self-employed individual commercial households" profession (11.7\%) and Korean respondents that serve as the "enterprise mid-level cadres" (15.4\%), "enterprise grassroots cadres"(14.1\%), "private entrepreneurs" (14.1\%) and "professional technical personnel "(11.5 percent) (Zhang, 2014).

\section{Qingdao: Korean Ethnic Migrants and Entrepreneurs}

According to our survey, at present, there are more than 8,000 South Korean enterprises in Qingdao, and nearly 100,000 Koreans work and live in Qingdao. Qingdao has become the city holding the largest number of Korean people. South Korea is one of the most important economic and trade partner of Qingdao. Therefore, there are 120,000 Korean minorities migrated from the Northeast (Yanji, Jilin) to Qingdao for working in the South Korean enterprises. Our survey shows: Korean minorities respondents are mainly distributed in three sectors: the "manufacturing" $(23.5 \%)$, the "food service industry" (15.3\%) and "trade"(14.1\%).

For example, Li Cang district, one of the four districts in Qingdao city, is the new administrative division of the city officially established in June, 1994, which consists of the original Li Cun of Laoshan district and most part of Cang Kou District. According to incomplete statistics, there were 21 ethnic minorities with a total of 4782 people in Licang District, including 3014 Korean ethnics, accounting for $63 \%$. At the northern end of Qingdao, Chengyang District, as the business gates for South Korean companies in Qingdao, holds the largest number of Koreans and Korean ethnics. In addition to the Korean factories, there are also more than 800 stores, of which more than $90 \%$ are hotels, KTVs and food shops and other service businesses. The Korean ethnics in Qingdao are drawn by the Korean investment to migrate to Qingdao. Their lives mainly depend on the South Korean enterprises.

Observing the whole society, how does Korean folk "beehive" society locate itself and play its role in governmental "umbrella society"? Government builds the stage and capital plays the role in the process of market transformation, it is impossible for powerless Korean migrant worker to build up his own "beehive" over night. They couldn't even rely on any relatives or friends, therefore the cost and risk are relatively high, in short, it is very unlikely for migrant workers to build up "beehive" in the first stage. Till the second stage, these Korean forgoers become queen bee and bring worker bees (relatives and friends) come to work in the cities, and it is qualified for them to build up their own chain "beehives". In the third stage, the network of Korean migrant workers is becoming wider and wider, the range has gone beyond the consanguinity or affinity and it is qualified to become net type "beehive". In a word, the main principle of Korean migrant workers self-built "beehive" is mutual help; it has two types of "chain type" and "net type". Korean folk "beehive" society becomes supplement part of Qingdao official "umbrella" society, they exist side by side and play a part together (Zhang, 2018).

A senior Korean man told us: The Korean minority people are mainly attracted by the South Korean enterprises due to convenience and language advantages. In 1993, the Korean enterprises began to recruit laborers from the north-east China. Most of the Korean ethnics work in factories, many of whom were engaged in the shoe-making, clothing, toy and sport utility industries. The elders tend to be nurses or 
cleaners, or work in the kitchen; while the younger ones work in the Korean factories, earning more than the Han people, with salary up to 5000-6000 yuan. Even those with the lowest income can earn 1500-2000 per month. There are also some Korean ethnic people working in Japanese factories, because many of the Korean ethnics used to learn Japanese in high schools providing them with an advantage in finding jobs. Jiaozhouwan was opened up later than Weihai. In Qingdao, initially the Korean came to Chengyang, then Laoshan and finally the downtown Qingdao. Now, there are many Koreans in Chengyang, Jiaozhouwan, Jimo and Pingdu, and they mainly live in Licun. There are many Korean enterprises here. Owing to the language advantage, our children work as interpreters in the Korean companies, and many of us settle down here following our children. Chengyang holds the most ethnic Korean population. Other Koreans scattered in Xifu, Xiazhuang, Liuting and others. Many of the young men work in the manufacturing sector, and some in the trade companies ${ }^{1}$.

In recent years, due to severe pollution, poor management and other reasons, coupled with the recent international financial turmoil, some South Korean-owned enterprises had to leave Qingdao. South Korean companies in Qingdao fell into stagnation or even decline, which greatly affected the foundation for the development of the Korean ethnic people. At present, for example, Chengyang receives the most Korean migrants, but a lot of them just came blindly and can't find a job.

In terms of employment and management, on the one hand, a lot of young Korean migrants work in the South Korean companies. After some time, they mastered the technology and craft, they would quit and start their own business, and some of them can even annex the original Korean-owned enterprises, particularly the handicraft processing industry. On the other hand, the Korean ethnic people have to solve the employment issue themselves because the government has no interest in doing that and the Han enterprises are generally unwilling to recruit Korean ethnics. If the South Korean companies once leave, many of the Korean ethnics will fall in impoverishment. ${ }^{2}$

Qingdao Korean ethnic immigrants are mainly employed in the procurement, production, sales, service and other economic areas or they operate their own businesses. Their economy is mainly transplanted from the Korean-owned export-oriented enterprises. The professionalism and business activities of the ethnics are necessary for the local economy, however their social and cultural life still retain their cultural identity, yet also actively absorb a variety of new cultural elements, such as the South Korea's modern corporate culture.

In religious aspect, Qingdao's Korean ethnics accepted Christianity from South Korea. Originally there were no Korean churches in Qingdao. Started in 1994, the first Korean ethnic church was established in Liuting by the Korean company S \& K. From the second half of 1994, the Korean ethnics began to join the Korean church activities with the South Koreans. The Korean church did not have any priest at first, so the South Korean churches send some over. However, the Chinese authorities are extremely unhappy about this. South Korean missionaries are willing to help, and now 80 percent of Bible are from South Korea. The Korean churches also provide us with many learning materials, but we dare not to accept them. Currently, the Korean ethnics have three churches in Qingdao ${ }^{3}$ organizing worship activities for the believers, trying to form their own ethnic religious culture. Our funding sources are from Korean Christians. In accordance with the provisions of the Bible, everyone should hand in 1/10 of personal income to the church. ${ }^{4}$

Our survey shows that: currently $66.7 \%$ of Korean ethnic respondents said they own an apartment in Qingdao City. 55.3\% of the Korean respondents said their dwelling space ranges from 71-100 square meters; $21.3 \%$ claim that dwelling space is more than 101 square meters. In fact, the origins of Qingdao's Korean minority are quite scattered, such as Harbin, Jiamusi, Qiqihar, Mudanjiang, Jixi, Ning, and Mishan of Heilongjiang province; Changchun, Yanji, Longjing, Hunchun, Jiaohe, Liuhe and etc. of Jilin province; Shenyang, Yingkou, Fushun of Liaoning province. No matter how scattered they were, now they voluntarily assemble together to form a new community.

A Korean elder told us: Qingdao is equivalent to the second Yanbian. In Qingdao, the Korean language and customs are retained and continuingly strengthened through children's education and the 
elders' community activities and other means. Baitong Community Elders Society has more than 60 members of the Korean ethnics. Baitong Community has more than 20 Korean residents, and many others living in nearby districts. The Korean ethnics properly assembled together, like Xita of Shenyang, where the Koreans live quite concentrated so that no matter learning language, or living environment, are all very convenient. If Koreans live dispersedly, then the language, customs and so on will soon be gone. Daily activities of our association include singing, dancing, playing cards, chess, mahjong, etc. Every Sunday afternoon, a reading party will be held ${ }^{5}$. As can be seen, many Koreans are ready to settle down in Qingdao for long-term working and living.

There are a few primary and secondary schools teaching Korean in Qingdao. We surveyed Qingdao Bishan Korean Elementary School ${ }^{6}$. According to the principal, Xu Yushan, the school is a private one under the guidance of the Education Bureau of Lee Chang District, Qingdao City. The school implements trilingual education: Korean, English and Chinese. Among all the 31 elementary schools in Li Chang district, Bishan school boasts of the Korean language teaching as a feature, and the English language teaching is also among the best, while math and Chinese teaching are on the middle level. The school offers many after-class activities, such as Korean traditional country music, long drum, fan dance and so on. The main enrollment targets are Korean ethnic children. The enrollment numbers of Han students are tightly controlled with each class shall not exceed three. Chinese, mathematics and English teaching apply the unified textbooks; Chinese, mathematics, and English are taught in Chinese by Han teacher; while Korean language, Morality, Art and Music are taught in Korean.

Overall, in terms of employment, management, marketing, finance, technology, customers, design, religion, international contacts and modern pop culture, the Korean ethnics show clear dependence on Korean companies and Christian churches. From several aspects, such as primary education, traditional cultural heritage and etc., we can deduce the "transplantation" characteristic of the Qingdao Korean ethnics. The Korean ethnic immigrants in Qingdao are forming a kind of "dependence-transplantation" economic-cultural pattern.

\section{Huhhot: Mongolian Ethnic Migrants and Entrepreneurs}

Recent years, with the help of its advantaged natural pasture, the dairy industry of Hohhot has developed rapidly and become a famous "dairy capital". Along with the rapid development of the economy and the urban infrastructure, the characteristic tourism also grows vigorously. There are many dining places (some of them are Mongolian Food Streets) and the business and service industry with Mongolian style also grow swiftly.

Batusuhe, a restaurant owner from the Xilinguole (Ximeng) believes that Mongolian catering industry in the cities have to innovate. The Mongolian meal should add in pepper, aniseed and various spices to cater to the urban taste. Originally the Mongolian food add just salt, and the flavor is good. But now it must add some flavors of Han people to meet the market's need. Another question is that the development of the Mongolian catering industry is quite mussy. For example, there is no industry standard. Every place has its own characteristics, and so, he suggests, the Mongolian catering industry should set up their own standard.

Batusuhe said: "I have three restaurants in Xi Meng. Now I intend to open the fourth, which will be the largest, 2000 square meters. I do not loan from banks and I try to integrate all the ethnic specialties and the original ecology into the restaurants. My red meat and dairy products are from Xi Meng. Here on the market there is a lot of fake stuff. Xi Meng has many original ecological products. But due to some conditions, a lot of things are limited. In the blood farm, all kinds of animals' blood are mixed together. However on the prairie of Xi Meng, animals are all raised separately. The Mongolian food industry has to take root on the grasslands, where horses, camels, all kinds of meat and weeds are abundant. Here there were too many restrictions. We cannot find a lot of raw materials we need. And the meat flavor here is not good because the cattle and sheep are all raised around the countryside, where the environment is polluted. 
The meat of the prairie tastes far better. I want to start a slaughterhouse, and we slaughter and cook for immediate consumption. I think the business will be definitely better."

The general manager of Bayinwori, Ma Quanxi told us: "In 2005, we established the Mongolian Meal Research Institute, which is a nonprofit non-governmental organization. We invested a lot of money into the research and development of Mongolian food. I formed this idea in 2002, at that time I solved the food and clothing problem, and also made some money every year. So I hoped to make a new height of my business. Mongolian food is healthy and nutritious. The people on the grassland are all very healthy and strong. Mongolian meals can definitely play a role in raising people's health and nutrition. Bayinwori must retain the tradition, but also has to innovate according to modern tastes. For example, based on innovation, we launch the Abalone Camel Palm as upscale dishes, each cost 40 yuan. We recently launched the hot pot, fresh lamb for the first floor lobby. If you do not innovate, the grade and level will stay low. At the same time, we also have to take the health and nutritional functions into consideration."

Ma Quanxi said: "This year (2008) we start a project led by the Mongolian Meal Research Institute to integrate the eastern, central and west Mongolian food together with support from Bayinhaori. I will lead the team, with assistance of the Inner Mongolia Agricultural University. This should be supported by the regional government and the state. Mongolia has a long history, many things we have to ask the elderly's advice. This year our main goal is to develop Mongolian Cuisines as a cuisine system. Mongolian cuisine is not among the 8 National Cuisine Systems. We hope to integrate and promote Inner Mongolian cuisines, making it the ninth largest cuisine system." 8

Whether can this "transplantation" pattern of economic and cultural changes of Hohhot Mongolian come to success mainly depends on whether the driving force of all levels of governments, entrepreneurs and consumers are strong enough or not and whether this transformation can meet the market demand innovatively in the process of migration. The migration and transformation did not cause local social and cultural conflicts because although there are differences between the pastoral Mongolian and the urban Mongolian, however, no matter pastoral or urban they are all Mongolian ethnic people, and the two do not have significant cultural differences. Thus, in the process of migrating to urban area, the pastoral Mongolian will naturally link the two areas, which leads to the "transplantation" of the Mongolian economic-cultural pattern. In another word, the origin and resettlement area will be connected together.

Therefore, we can see, in Hohhot, a city known as "Green Town", the Mongolian migrants are gradually transplanting the distinctive Mongolian culture to the modern life, and trying to commercialize and marketize the Mongolian material and the intangible cultural resources to establish a new Mongolian economic-cultural pattern in line with modern metropolis. For example, the daily diet of the Mongolian is highly related to the ecological environment, natural resources, cultural characteristics, religious beliefs and so on. The Mongolian economic-cultural pattern is transformed from the original ecology to market-oriented with its impetus coming from all levels of government, entrepreneurs and consumers.

\section{CONCLUSION AND DISCUSSION}

\section{The Role of Ethnic Enterprises and Entrepreneurs in the Formation of New Economic- Cultural Pattern}

Based on my investigation and observation among the above six ethnic groups in the above four cities, I consider there are three types of business "beehives": (1) family "beehive": family-centered mutual benefit network, (2) value chain type of "beehive": win-win network centered by value chain, (3) ethnic "beehive": mutual benefit network based on minority groups. The growth of these private ethnic enterprises does not only depend on economic ability but also social cultural background. Private ethnic enterprise and manager have ethnic resources like distinct ethnic culture, language, value concept, kinship and community relations. These distinct characters help them to build up various "beehives" to obtain entrepreneurship capital, low costs labor, business credit and develop them into business and management activities after they left home. These various relation networks have something in common that is the 
existence of queen bee (leader). The leader is like the "King without crown", who serves as certain leading or directing functions inside the circle. They could be the head of a household, elder with high prestige or sometimes very successful businessman. More and more successful ethnic enterprises and mangers are gathering together and become ethnic enterprise group based on human relations of various family "beehives" and value-chain "beehives" (Zhang, 2018).

Among all the factors that influence the forming of the economic-cultural patterns, the ethnic enterprises and entrepreneurs play the most important and substantial roles, which epitomize the ethnic minority's livelihood strategy and economic strength in the city. Ten years ago, I asked an officer who worked at the central government: "If take an animal as metaphor, what do the ethnic enterprises in China look like?" He replied: "Butterfly. Because they are very weak and fragile, people usually make them, or treat them as 'specimens'. I said: "This is one side of it. The other side is that the worm pupates into 'butterfly'."

The growth of ethnic enterprises and entrepreneurial is not castle in the air. They have a certain ethnic resources, such as the significant cultural identity, national values, family, community, social networks, etc. These features and advantages guarantee the success of business after they migrate to the resettlement place (Aldrich \& Roger, 1990). Chan Kwok Bun pointed out that facing with the cruelty and hostility of reality in the host society, Chinese immigrants often use their kinship and social networks to raise funds, venture capital and gain financial credit. Chinese enterprises in the past were, and still are, established among the same tribes, especially families and relatives (Chan, 1991). For cultural, economic and ethnic division of labor reasons, the principal North American Chinese restaurants mainly use Chinese workforce. Peter Li argues that Chinese restaurant owners often have to work as hard as his relativeswaiters, thus blurring the boundaries between the employers and employees (Li, 1976).

Furthermore, in the process of transformation of ethnic migrants' economic-cultural pattern, the number, the economic strength and the industry concentration degree of the ethnic enterprises form an inflexible standard judging the success of the transformation. Accordingly, the entrepreneurial qualities, quantities, courage, economic strength and social influence are also key factors in the transformation of the economic-cultural pattern. Conversely, if an ethnic migrant group scatters all over the city in various industries just as ordinary workers, and has yet to set up their own ethnic enterprises and does not have entrepreneurs at all, then how do this ethnic group change or create their economic-cultural pattern?

In Qingdao, from the view of government policies, employment and business, education, religious life, community society, language and traditional cultural heritage and other aspects, although the Korean ethnics' economic-cultural pattern presents a new prototype, "dependent-transplantation"', we cannot assert its true content and form. Among them, the most fundamental fact is that Qingdao's Korean ethnics are mostly professional managers or common employees in South Korean enterprises, yet there did not appear a large number of Korean ethnical enterprises or entrepreneurs. For example, in religion aspect, Korean ethnic in Qingdao are merely spokespersons or agents of the Korean Christian. They have not formed their own independent Christian organization. In other words, in fact, their influence and social organizing force is not strong enough to form a new type of economic-cultural pattern with ethnic characteristics.

Without innovation, the "transplantation" economic-cultural pattern is meant to wither. The pastoral Mongolian left the ranch to the city and innovatively established commercialized food service, ethnic handicrafts trade and other economic activities, which have been proved to be an innovative way to build a new prototype of economic-cultural pattern. The economic-cultural pattern of Hohhot Mongolian migrants' "urbanization and marketization of prairie products" is the "innovation- transplantation" type. Hohhot Mongolian immigrants are forming relatively concentrated business area. Mongolian ethnic enterprises and entrepreneurs in the urban economy are forming an out-looking economic model: on one end is the grassland and pasture, on the other end is the greater China inland and the international markets. In terms of their social and cultural life, on the one hand it has a relatively closed nature with the development in their own independent space, on the other hand it shows a certain compatibility and 
becomes the "articulation" between area of origin a nd the resettlement areas, between the urban and rural areas, the tradition and modernity. The dichotomy does not apply to them anymore. Their economic-social identity and cultural identity have reflected multiplicity in nature.

For ethnic entrepreneurs originated from remote ethnic areas, the ethnic characteristic business is their major paths. These ethnic people start their own business alone or with partners, it not only increases the survival and development opportunity, but also brings unique ethnic culture to the city life. Thus, we analogize that the ethnic migrants in China have to transform or create their own economic-cultural patterns. Ethnic enterprise is a form of social organization, and the social foundation for changing or creating the ethnic economic-cultural patterns. Without such entity as the structural basis, the new type of economic-cultural pattern will have no foothold. Depending on the enterprises, the ethnic entrepreneurs can utilize their own cultural identity, ethnic values, family and community social networks to venture capital, gain cheap labor and commercial credit, etc., creating a favorable environment for the development of the ethnic enterprises. "Ethnic character" is an important condition for market access and also a significant competitive advantage. The "ethnic character" shows very distinct personality, which attracts customer's attention. These characteristic entrepreneurs exactly fill in the "blank" or "gap" of market's diversification demand, and build up a kind of ethnic "beehive society" with "ethnic enclave" or the "ethnic socio-economic enclave".

\section{ENDNOTES}

1. Source: from the interview at a church in Licang district, Qingdao. He was one of the earliest Korean immigrants here. In 1994, he used to work in a factory. Later the factory went bankrupt, he started to do some trade business. Now he retired and entered into the church, though the church stuff was hard to maintain, he tries his best to do the job.

2. Source: Cui Yongji's speech in a residential committee symposium on January 14, 2008.

3. Li Cang District has two churches: one is Wenchangge church, which has 110 Christians; the other one is Zhengdinglu church, about 100 people; Laoshan district has one Christian church, more than 200 people.

4. Source: I intervivewed Cui Yongji twice, first time in the Wenchangge church on January 13, 2008 and on January 14 in Cui Yongji's home.

5. During the survey in Qingdao, with the help of Baitongyuan residential commettee, a large commercial residential area, the survey team members held a symposium with the elderly association members (they are all Koreans) on January 14, 2008. The elderly association is in fact a Korean folk organization in Qingdao. The President of this organization is from Yingkou, liaoning province. He used to serve in the army for seven years and retired as a captain. Now he lives with his children. His has four children, two of them working in Qingdao.

6. Source: I interviewed Xu Yushan, the principal of Bi Shan Korean Elementary School on January 10, 2008. The headmaster's office has a slogan: "dedicated in the ethnic education career, establish a environment for the 200000 Korean children in Qingdao to learn their native language".

7. Source: from the interview of Mr. Batusuhe, the boss of Qingkeerhada, on January 17 and January 19, 2008.

8. Source: From the interview of Mr. Ma, manager of Bayinhaoriwo on Jan.19,2008.

9. Korean migrants obtain employment or start their own business in the procurement, production, sales, service and other areas of the economy, thus become dependent in the city 's economy. Their professions and business activities are necessary to the local economy development. Their social and cultural life retain their own ethnic or regional characteristics of tradition, but also actively absorb a variety of new cultural elements of urban life, trying to form their own new ethnic or regional culture. 


\section{REFERENCES}

Aldrich, Howard \& Roger Waldinger. 1990. "Ethnicity and Entrepreneurship", Annual Review of Sociology, Vol. 16:111-135.

Chan, Kwok Bun.1991. Smoke and Fire: Montreal Chinese. Chinese University of Hong Kong Press.

Chan, Kwok Bun \& Claire Chiang See Ngoh, 1994. Stepping Out: The Making of Chinese Entreprenuers. Simon \& Schuster (Asia) Ltd.

Hao, Shiyuan, Ethnic Issues in the Construction of an Ethnic Country, in China Ethnic News, 2007.01.16

Joyce, Patrick D., 2003. No Fire Next Time: Black Korean Conflicts and the Future of America's Cities. Ithaca, NY: Cornell Univ. Press.

Kwong, Peter, 1979. Chinatown New York: Labor and Politics (1930-1950). New York: Monthly Review Press,.

Kwong, Peter, 1987. New Chinatown: Modern Chinese Communities in U.S. WAP Press.

Li, Peter S.1976. "Ethnic businesses among Chinese in the U.S." . Journal of Ethnic Studies Vol. 4: 35-41.

Lee J., 2002. Civility in the City: Blacks, Jews, and Koreans in Urban America. Cambridge, MA: Harvard Univ. Press.

Light, Ivan. 1972. Ethnic Enterprises in America: Business Welfare among Chinese, Japanese, and Blacks. University of California Press.

Light, Ivan and Steven Gold. 2000. Ethnic Economies. San Diego: Academic Press.

Nee, V. and B. Nee. 1973. Longtime California: A Study of an American Chinatwon. Standford University Press.

Portes, Alejandro and Robert L. Bach. 1985. Latin Journey: Cuban and Mexican Immigrants in the United States. Berkeley: Univ. of California Press.

Weitzer, Ronald. 1997. "Racial prejudice among Korean Merchants in African American Neighborhoods". Sociological Quarterly. Vol. 38:587-606.

Wong, B. P. 1988. Patronage, Brokearge, Entrepreneurship, and the Chinese Community of New York. New York: AMS Press.

Yoon, I.J. 1997. On My Own: Korean Businesses and Race Relations in America. Chicago: University Chicago Press.

Zhang, Jijiao. 2009, "The Orientation of Urban Migrants' Social Network: A Comparative Survey on Six Minorities in the Cities of China", Chinese History and Society, Vol.35. Berliner China-Hefte, Germany, pp. 127-139.

2012. "Migrant Social Networks: ethnic Minorities in the cities of china", in Wind over Water: Migration in an East Asian Context. Edited by David Haines, Keiko Yamanaka, and Shinji Yamashita. USA, New York: Berghahn Books, Chapter 3, pp.47-59.

2014. "The economic-cultural patterns of ethnic minority migrants in the cities of China", Malaysian Journal of Chinese Studies, Vol. 3, No. 2, 2014: 67-85.

2016. The "Umbrella Society": A New Concept for Observing Social-Economic Structural Transition in China, International Journal of Business Anthropology (by Cambridge Scholars Publishing), Volume 6 (2), pp. 83-102.

2018. Beehive Society: A New Concept for Observation of China's Social- economic Transformation, International Journal of Anthropology and Ethnology, by Springer-nature. Nov.Vol.2.

Zhang, Jijiao and Yin Peng, 2013, "Ethnic Migrants' Employment and Industry Distribution in the Cities of China", The Review of Black Political Economy (ISSN 0034-6446), New York: Springer Science Business Media, April Volume, pp. 81-106.

Zhou, Min. 1992, Chinatown: The Socioeconomic Potential of an Urban Enclave, Philadelphia: Temple University Press. 